\title{
Spectral Behavior of White Pigment Mixtures Using Reflectance, Ultraviolet-Fluorescence Spectroscopy, and Multispectral Imaging
}

\author{
Lucilla Pronti ${ }^{1,2}$, Anna Candida Felici', Matthieu Ménager², \\ Cathy Vieillescazes ${ }^{2}$, and Mario Piacentini'
}

\begin{abstract}
Reflectance spectroscopy, ultraviolet (UV)_fluorescence spectroscopy, and multispectral imaging have been widely employed for pigment identification on paintings. From ancient times to the present, lead white, zinc white, and titanium white have been the most important white pigments used for paintings and they are used as pigment markers for dating a work of art. The spectral behavior of these pigments is reported in several scientific papers and websites, but those of their mixtures are quite unknown. We present a combined nondestructive approach for identifying mixtures of lead white, zinc white, and titanium white as powder and dispersed in two different binder media (egg yolk and linseed oil) by using reflectance spectroscopy, spectrofluorimetry, multispectral reflectance and UV-fluorescence imaging. We propose a novel approach for mapping the presence of white pigments in paintings by false color images obtained from multispectral reflectance and UV-fluorescence images. We found that the presence of lead white mixed with either zinc white or titanium white is highly detectable. Zinc white mixed with lead white or titanium white can be identified due to its UV-fluorescence emission, whereas titanium white in association with lead white or zinc white is distinguishable by its reflectance spectral features. In most cases, the UV-fluorescence analyses also permit the recognition of the binder media in which the pigments are dispersed.
\end{abstract}

\section{Keywords}

Multispectral imaging, white pigments, reflectance spectroscopy, fluorescence spectroscopy

\section{Introduction}

White pigments are the most widely employed pictorial materials encountered in easel paintings since they are used to obtain light hues. Although they were generally blended with colored pigments, different white pigments were often mixed together in order to improve the aesthetic qualities of the white color. For example, when zinc white was added to lead white, the pictorial layers preserved good optical properties due to the stability of zinc white in photo-ageing processes.'

In modern times, lead white, zinc white, and titanium white have been the most important white pigments used for paintings. Among them, lead white was the only white pigment employed in European easel paintings until the 19 th century. ${ }^{2}$

Lead white pigment is a basic $\mathrm{Pb}(\mathrm{II})$ carbonate, $\mathrm{PbCO}_{3}$ $\mathrm{Pb}(\mathrm{OH})_{2}$, and it has been used for white pictorial layers, in mixtures with other pigments and in the "imprimitura" (canvas primer). As a pictorial layer, lead white was ground in oil or in egg tempera (the latter procedure was often used in the early Italian panel paintings) and it presents a high hiding power, even in oil, due to its high refractive index.

Despite its use in modern paintings, the toxicity of lead white led to its progressive abandonment, which began with the introduction of zinc white in 1780.' The zinc white pigment is a zinc oxide, $\mathrm{ZnO}$, known since antiquity. However,

\footnotetext{
'Department of Basic and Applied Sciences for Engineering, SapienzaUniversity of Rome, Rome, Italy

${ }^{2}$ Restoration Engineering of Natural and Cultural Heritage, IMBE laboratory, Avignon University/CNRS/IRD/AMU, Avignon, France
}

\section{Corresponding author:}

Lucilla Pronti, Department of Basic and Applied Sciences for Engineering, Sapienza-University of Rome, via Antonio Scarpa 14, 0016I, Rome, Italy. Email: lucilla.pronti@uniromal.it 
zinc white only appears in paintings at the end of the 18th century. It presents approximately the same refractive index of lead white, but it has less hiding power in oil. ${ }^{1}$

In the 1920s, titanium white was introduced. Titanium white pigment is a titanium dioxide, $\mathrm{TiO}_{2}$, existing in two different crystallographic forms: anatase and rutile. Originally, painters mostly employed anatase due to the difficulty of producing synthetic rutile; the latter became commercially available only in the second half of the 20th century. ${ }^{3}$

The modern production of color tubes on an industrial scale has led to the creation of heterogeneous pictorial materials, in which the pigments are generally mixed together, as demonstrated by the technical details of the manufacturers and by analytical studies. ${ }^{4}$

For the white tubes, for example, a new pigment was produced, named flake white, which is a mixture of lead white and zinc white. ${ }^{5}$ Other mixtures were found in modern paintings, such as the titanium white-zinc white mixtures used by Jackson Pollock ${ }^{6}$ or mixtures of lead white and titanium white. ${ }^{7}$ Some of these colors have been used for restoration in modern and contemporary times. Hence, the identification of the white pigment used in a pictorial layer or in a white pigment mixture can be fundamental for dating a painting and/or for investigating restoration materials. For this purpose, the nondestructive analytical techniques for pigment identification are preferred by art historians because they do not involve sampling of the analyzed layer.

Among all portable nondestructive techniques, X-ray fluorescence (XRF) spectroscopy is probably the most specific analysis, but despite its low cost and ease of use, it reveals very small portions of the painting $\left(I-3 \mathrm{~mm}^{2}\right.$ maximum) ${ }^{8-10}$ However, recently, portable scanning macro XRF devices have been developed to map the elemental distribution on paintings in situ. "I

Raman and infrared (IR) spectroscopies are also used for the identification of white pigments on paintings, but again they are punctual analyses. ${ }^{12-19}$ In recent years, macro-mapping IR imaging has been employed, but only in cross-sections. ${ }^{20}$ The reflectance and the UV-fluorescence spectroscopies have been used for pigment identification, ${ }^{21-26}$ but their potential for the identification of white pigment mixtures are still unexplored.

A traditional approach is the use of UV-fluorescence photography, ${ }^{27-30}$ but in this case, it is difficult to distinguish the spectral features due to the nonlinear spectral sensitivity of the color camera.

In recent years, multispectral and hyperspectral imaging methods are replacing traditional ultraviolet visible (UV-Vis) spectroscopy and UV-fluorescence photography due to the possibility of mapping the presence of pigments with the acquisition of UV-fluorescence and reflectance spectroscopic images. ${ }^{31-34}$ However, the spectral changes of a white pigment mixed with other white pigments are unexplored. For example, zinc white exhibits two fluorescence bands centered at $380 \mathrm{~nm}$ and $500 \mathrm{~nm}$, respectively, but to our best knowledge no work has been published on the possibility for using these spectroscopic features as a fingerprint for the presence of zinc white in mixtures with other white pigments. ${ }^{35,36}$

The aim of this work is to characterize the spectral behavior of white pigment mixtures in different binders (egg yolk and linseed oil) by means of nondestructive techniques in order to investigate the potentiality of UV-fluorescence spectroscopy, reflectance spectroscopy, and multispectral imaging for the identification of white pigments mixtures used as pictorial layers.

\section{Experimental}

\section{Materials}

We prepared six pictorial samples using three white pigments: lead white, zinc white, and titanium white, mixed with two different binders: egg yolk and linseed oil. For this study, we used the lead white pigment (Kremer Pigmente), the zinc white and the rutile titanium white pigments (Zecchi, Florence, Italy), and linseed oil (Lefranc and Bourgeois).

Eighteen samples were prepared mixing two white pigments with different ratios $(30: 70,50: 50$, and $70: 30$ percent by volume). Each unmixed and each mixed sample $(0.40 \pm 0.1 \mathrm{~g})$ was combined with linseed oil $(0.20 \pm 0.03 \mathrm{~g})$ for the oil samples or with chicken egg yolk $(0.04 \pm 0.02 \mathrm{~g})$ and distilled water in order to obtain a good spreading property. For the lead white in egg yolk, we prepared two samples with different quantities of the binder. All the samples were spread on microscope slides, as shown in Figure I.

All the samples were analyzed immediately after spreading; the oil samples were analyzed again once completely dried after two months of storage in the darkness at room temperature.

\section{Methods}

\section{Reflectance Spectroscopy}

Reflectance measurements were carried out with a portable integrating sphere spectrophotometer (Minolta CM-2300d). It performs measurements at $d / 8$ geometry (diffuse illumination, $8^{\circ}$ viewing angle) and we performed the measurements in specular component excluded (SCE) mode. The light source was composed of two pulsed xenon lamps (X4) and the detector was a silicon photodiode array (dual 40 elements) with a diffraction grating for dispersing the light. This spectrometer covers the wavelength range of $360-740 \mathrm{~nm}$ at acquisition steps of $10 \mathrm{~nm}$.

\section{Spectrofluorimetry}

We acquired the fluorescence spectra by means of a spectrometer with a xenon lamp as the excitation source 


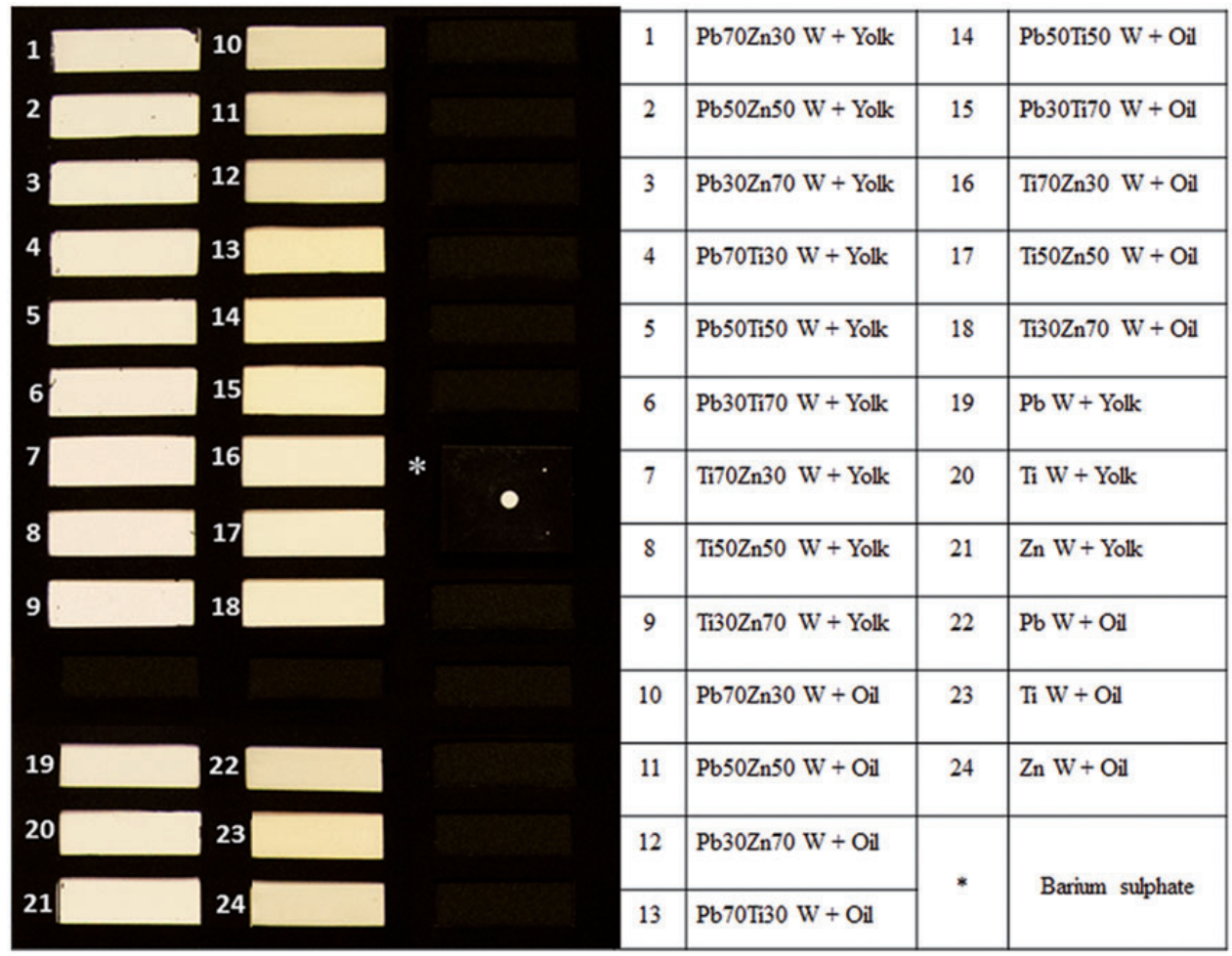

Figure I. Analyzed samples.

(Horiba FluoroMax-2). The device is equipped with a solid sample holder that allows spectral acquisitions directly on sample laying on microscope slides. The samples were positioned with an angle of $75^{\circ}$ with respect to the excitation source and $25^{\circ}$ with respect to the detector to reduce the specular reflection of the excitation source. The fluorescence spectra were acquired at steps of $2 \mathrm{~nm}$ exciting at $365 \mathrm{~nm}$. The slits were fixed at $3 \mathrm{~nm}$ bandpass for the excitation and $2.5 \mathrm{~nm}$ bandpass for the emission.

\section{Multispectral Imaging}

The multispectral imaging was performed with a monochromatic camera (QSI 583-w) equipped with a MicroNikkor optical system and ten Thorlabs narrow band interferential filters (full width half-maximum [FWHM] of $10 \mathrm{~nm}$ ) with the central wavelengths at $380 \mathrm{~nm}, 390 \mathrm{~nm}$, $400 \mathrm{~nm}, 410 \mathrm{~nm}, 420 \mathrm{~nm}, 450 \mathrm{~nm}, 470 \mathrm{~nm}, 500 \mathrm{~nm}$, $550 \mathrm{~nm}$, and $600 \mathrm{~nm}$. All of the multispectral images were properly calibrated using dark and flat frames. Furthermore, the multispectral UV-fluorescence images were radiometrically calibrated; this means that all the images were corrected by the spectral sensitivity of the charge-coupled device camera and the spectral transmittance of the optical lens and the filters. ${ }^{37}$

For the reflectance imaging, we used two halogen lamps and two white LED lamps, whereas for the UV-fluorescence imaging we employed two UV lamps constituted by three
UV LEDs (High Power LED M365DI, Thorlabs) for each lamp, characterized by a spectral emission peaked at $365 \mathrm{~nm}$ with a FWHM of $10 \mathrm{~nm}$, and an optical output power of $190 \mathrm{~mW}$ each LED. The sources were placed at $\pm 45^{\circ}$ with respect to the normal samples, following the standard illumination geometry for imaging. A pure barium sulfate pellet was used as reflectance standard.

\section{Results and Discussion}

\section{Reflectance Spectroscopy and Spectrofluorimetry}

The reflectance spectra measured on the unmixed white pigments mixed with either egg yolk or linseed oil are reported in Figure 2.

\section{Zinc White}

The reflectance spectra of zinc white have a steep rise with inflection point at $384 \mathrm{~nm}$, followed by a shoulder around $400 \mathrm{~nm}$. The inflection point and the shoulder remain roughly in the same positions regardless of the binder used, as clearly shown in Figure 2a.

In the visible range, the reflectance of the oil paints is lower than the tempera ones (paint prepared with egg yolk). After drying for two months in the darkness, the reflectance spectrum of the oil paint presents two shoulders: one around $400 \mathrm{~nm}$ and a second weak one around $470 \mathrm{~nm}$. 

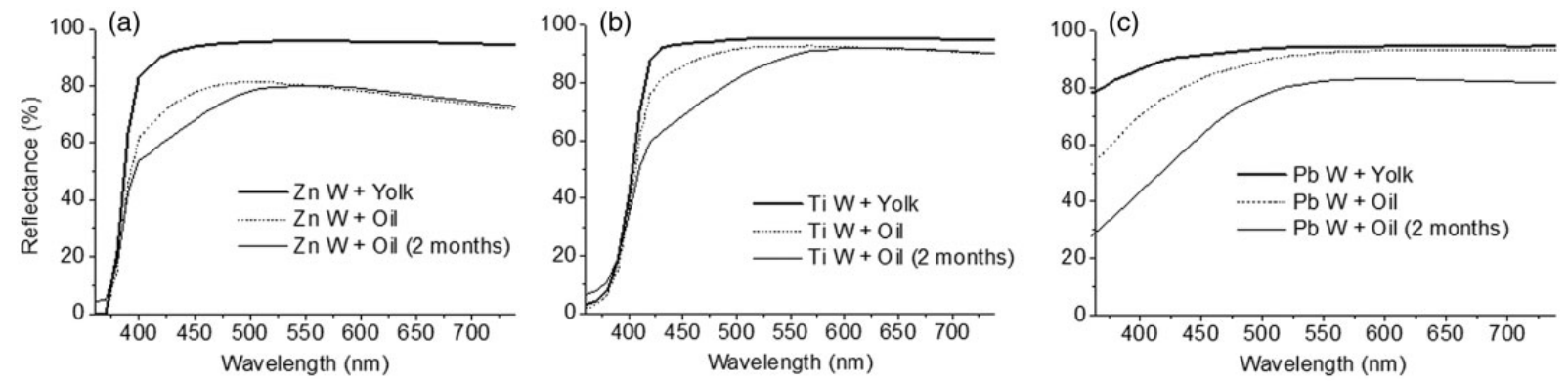

Figure 2. Reflectance spectra of zinc white (a), titanium white (b), and lead white (c) mixed with egg yolk (Yolk) or linseed oil (Oil). The measurements performed on the oil samples after two months of storage in darkness.
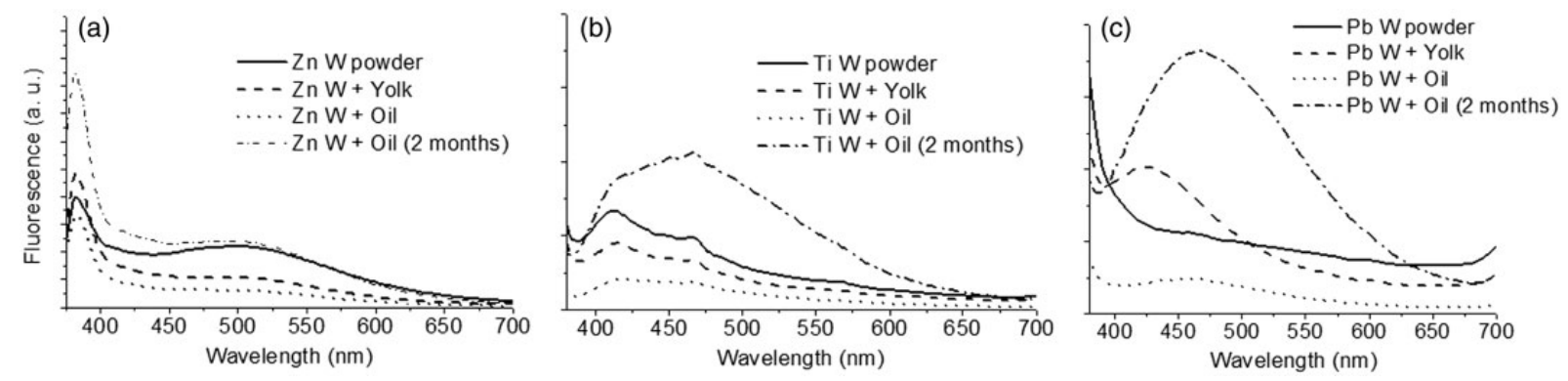

Figure 3. Fluorescence emission of zinc white (a), titanium white (b) and lead white (c) as powder and mixed with egg yolk (Yolk) or linseed oil (Oil). The measurements performed on the oil samples after two months of storage in darkness.

The fluorescence emission of zinc white (Figure 3a) presents a narrow UV emission band, with the maximum centered at $380 \mathrm{~nm}$, and a broad band between $460 \mathrm{~nm}$ and $580 \mathrm{~nm}$, with the maximum at about $500 \mathrm{~nm}$. Moreover, the type of binder does not induce any significant band shift on the fluorescence spectra.

\section{Titanium White}

The reflectance spectra of titanium white (Figure $2 b$ ) have a steep rise with an inflection point at $404 \mathrm{~nm}$ for all binders used. The fluorescence emission of titanium white is characterized by a broad structured band from $400 \mathrm{~nm}$ to $500 \mathrm{~nm}$ with two weak bands centered at $412 \mathrm{~nm}$ and $466 \mathrm{~nm}$, respectively, for all binders. Such a high number of emission bands led a very characteristic structure of the titanium white fluorescence spectra. The fluorescence emission in the oil sample changes significantly after two months of storage in darkness: a new, strong fluorescence band appears in the $400-600 \mathrm{~nm}$ range (Figure $3 \mathrm{~b}$ ).

\section{Lead White}

The reflectance spectra of lead white mixed with egg yolk or linseed oil show a weak absorbance centered around $380 \mathrm{~nm}$. The low absorbance intensity explains its whiter color in comparison with the other two white pigments (Figure 2).
After two months of storage in darkness, the absorbance of degraded oil covers the weak signal of lead white.

The fluorescence emission of the lead white powder shows the tail of an emission band lying below $375 \mathrm{~nm}$ and it becomes quite flat between 425 and $675 \mathrm{~nm}$ (Figure 3c). The fluorescence spectra of paint samples are deeply linked with the nature of the binder. Tempera paints, prepared with egg yolk, show an additional fluorescence emission band with the maximum at $420 \mathrm{~nm}$; the fluorescence of linseed oil paints is much weaker, with the maximum of the second emission band at $468 \mathrm{~nm}$. After two months of storage in darkness, we observed a strong increase of the intensity of the $468 \mathrm{~nm}$ band, clearly due to the ageing of the linseed oil.

\section{Lead and Zinc Whites}

The reflectance spectra of the lead and zinc white mixtures, containing up to $70 \%$ of lead white in volume, present similar spectral features as unmixed zinc white paints (Figure 4a). In this way, we notably observed the characteristic absorption band of zinc white in the UV range. In addition, all the oil samples show an increase in reflectance with respect to the unmixed zinc white spectrum above $500 \mathrm{~nm}$, probably due to the higher lead white reflectance.

The fluorescence emissions of the lead and zinc white mixtures show a spectral behavior similar to that of the zinc 

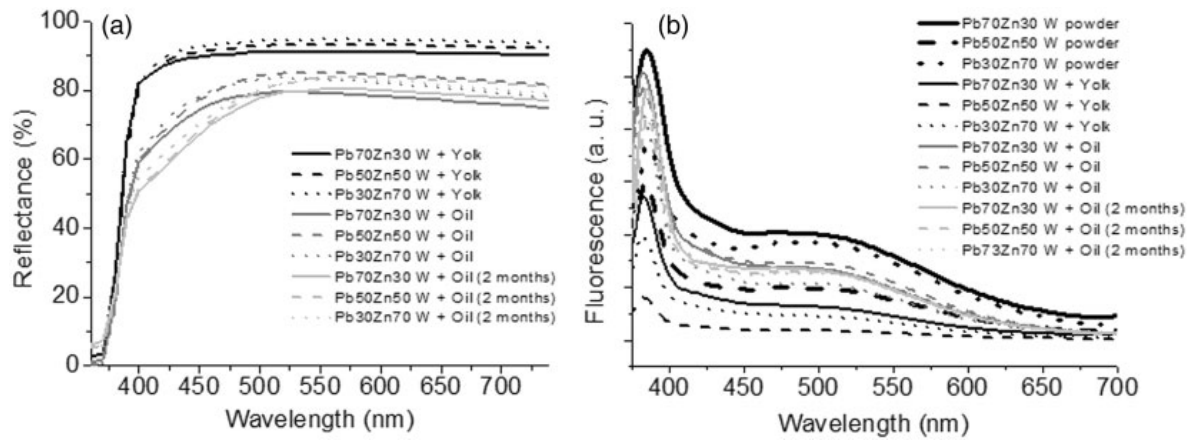

Figure 4. Reflectance spectra (a) and fluorescence spectra (b) of mixtures of lead white and zinc white with egg yolk (Yolk) or linseed oil (Oil). The measurements performed on the oil samples after two months of storage in darkness. The fluorescence spectra were acquired exciting at $365 \mathrm{~nm}$.
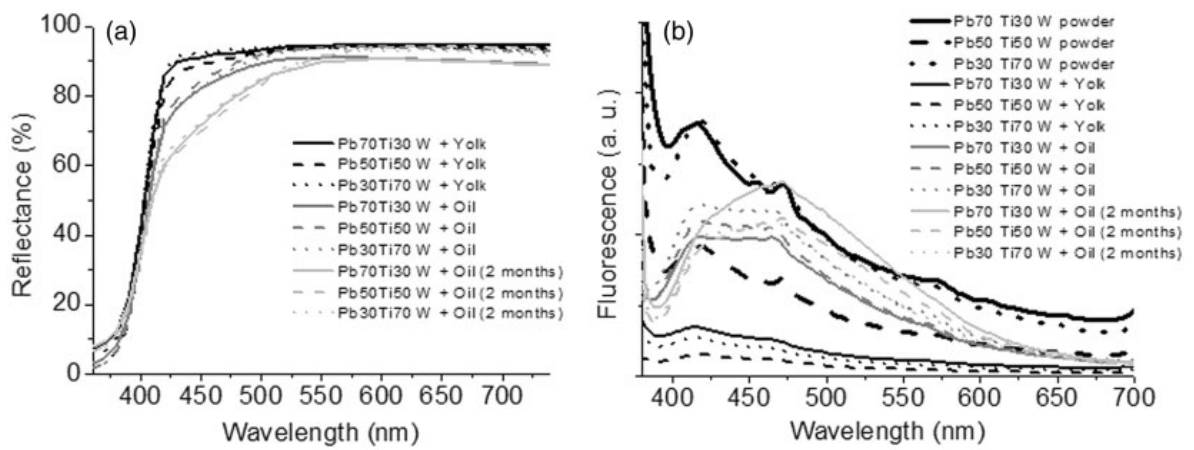

Figure 5. Reflectance spectra (a) and fluorescence spectra (b) of mixtures of lead white and titanium white with egg yolk (Yolk) or linseed oil (Oil). The measurements performed on the oil samples after two months of storage in darkness. The excited fluorescence spectra were acquired at $365 \mathrm{~nm}$.

white paints. The broad band at long wavelengths is less distinguishable in egg yolk samples (Figure 4b).

\section{Lead and Titanium Whites}

The reflectance spectra of the lead white and titanium white mixtures present the same spectral features of the titanium white samples, up to $70 \%$ of lead white in volume (Figure 5a). In spite of the presence of the lead white, an absorption band is present in the UV range, alike unmixed titanium white samples. The oil samples present a reduction of the reflectance in the blue region.

The fluorescence spectra reveal that the intensity of the fluorescence emission at $466 \mathrm{~nm}$ increases in the dried oil samples, alike the unmixed titanium white. For this reason, we can distinguish samples prepared with egg yolk from those prepared with linseed oil (Figure 5b).

\section{Titanium and Zinc Whites}

The reflectance spectra of the zinc white and titanium white mixtures (Figure 6a) present the same spectral features as the reflectance spectra of titanium white, implying that if the titanium white pigment is combined with either lead white or zinc white, we cannot recognize the presence of the last ones with the reflectance measurements only.

On the contrary, the fluorescence spectra show the spectral features of both zinc white and titanium white. For the two-month-old dried oil samples, we observe an increase of the fluorescence emission, in particular at long wavelengths (Figure 6b).

\section{Multispectral Images}

The multispectral reflectance and fluorescence images were acquired on the egg yolk and oil samples after two months of storage in darkness. In order to reduce the redundancy of information that multispectral imaging can often produce, we have chosen to show the results by means of "false" color (RGB) images that depicts the samples in colors that differ from those of a photograph (a true-color image). We define this method as "false" RGB image to distinguish it from the true false RGB image that is a rendering method already used for the identification of the pigments in paintings, in which the red component of the RGB image is substituted with the IR image, the green with the red, and the blue with the green. ${ }^{38}$ 

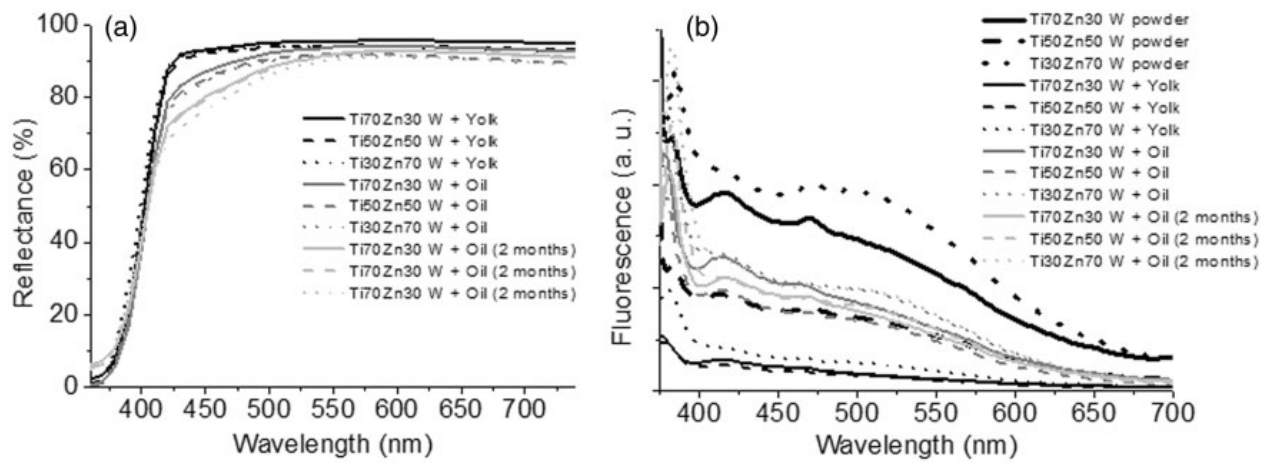

Figure 6. Reflectance spectra (a) and fluorescence spectra (b) of mixtures of titanium white and zinc white with egg yolk (Yolk) or linseed oil (Oil). The measurements performed on the oil samples after two months of storage in darkness.

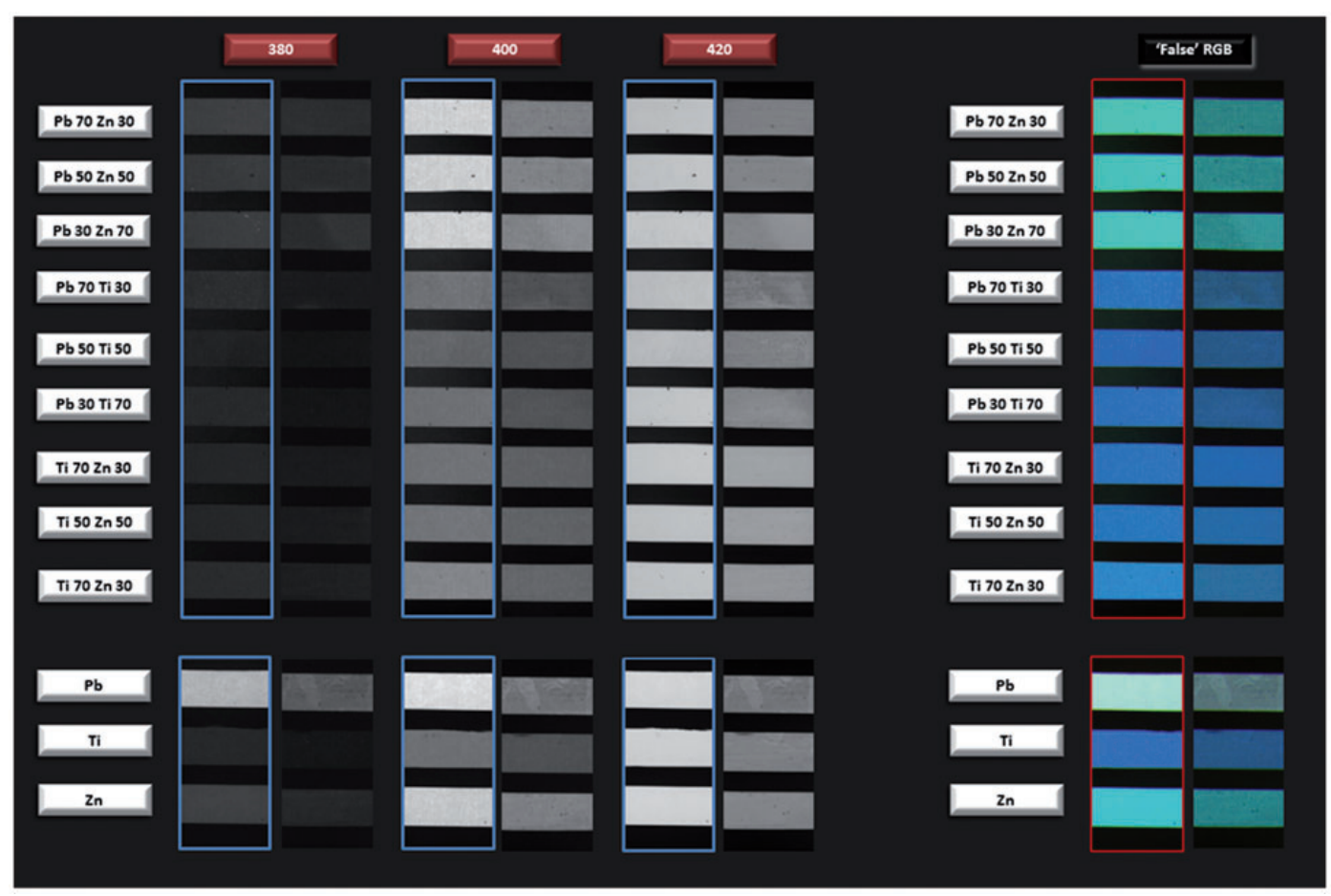

Figure 7. Multispectral images at $380 \mathrm{~nm}(\mathrm{R}), 400 \mathrm{~nm}(\mathrm{G})$, and $420 \mathrm{~nm}$ (B) of the white mixtures (left panel) and "false" RGB combination of the same images. The yolk samples are framed in blue in the multispectral images and in red in the false RGB image.

The false color images were selected on the basis of the results of the reflectance measurements and of the fluorescence spectra, three multispectral images in which the differences between the spectral features of the samples are more pronounced

In the case of multispectral reflectance imaging, we have chosen the filters centered at $380 \mathrm{~nm}$ and $400 \mathrm{~nm}$ corresponding to the inflection points of the reflectance spectra of zinc white and titanium white, respectively, and one centered at $420 \mathrm{~nm}$ that transmits a wavelength range in which the reflectance values of all the samples differ mostly from each other.
For the multispectral fluorescence imaging, we have chosen the filters, centered at $420 \mathrm{~nm}$ and $470 \mathrm{~nm}$, that correspond to the emission band of the titanium white samples and the dried lead white in oil (Figure 3). For the third image, although the fluorescence maximum in the visible range of zinc white samples is at about $500 \mathrm{~nm}$, in this range we have also strong fluorescence emitted by the other pigments, instead, at about $530 \mathrm{~nm}$, the fluorescence intensity of the zinc white samples is still rather strong and definitely different from that of the other ones. Even if zinc white samples present an intense fluorescence emission at $380 \mathrm{~nm}$, we have avoided the multispectral fluorescence false 
Table I. False RGB values of the reflectance images taken at $380 \mathrm{~nm}(\mathrm{R}), 400 \mathrm{~nm}(\mathrm{G})$, and $420 \mathrm{~nm}$ (B) of the white samples and their mixtures.

\begin{tabular}{|c|c|c|c|c|c|c|c|}
\hline $\begin{array}{l}\text { Samples } \\
\text { with yolk }\end{array}$ & $\mathrm{R}$ & G & B & $\begin{array}{l}\text { Samples } \\
\text { with oil }\end{array}$ & $\mathrm{R}$ & G & B \\
\hline $\mathrm{Pb} 70 \mathrm{Zn} 30$ & $64 \pm 2$ & $215 \pm 3$ & $195 \pm 2$ & $\mathrm{~Pb} 70 \mathrm{Za} 30$ & $48 \pm 1$ & $132 \pm 1$ & $129 \pm 2$ \\
\hline $\mathrm{Pb} 50 \mathrm{Zn} 50$ & $57 \pm 3$ & $213 \pm 2$ & $199 \pm 2$ & $\mathrm{~Pb} 50 \mathrm{Zn} 50$ & $46 \pm 1$ & $135 \pm 2$ & $134 \pm 1$ \\
\hline $\mathrm{Pb} 30 \mathrm{Zn} 70$ & $60 \pm 2$ & $216 \pm 2$ & $203 \pm 2$ & $\mathrm{~Pb} 30 \mathrm{Zn} 70$ & $49 \pm 4$ & $142 \pm 6$ & $|4| \pm 6$ \\
\hline $\mathrm{Pb} 70 \mathrm{Ti} 30$ & $46 \pm 2$ & $117 \pm 4$ & $195 \pm 3$ & $\mathrm{~Pb} 70 \mathrm{Ti} 30$ & $33 \pm 1$ & $87 \pm 1$ & $128 \pm 4$ \\
\hline $\mathrm{Pb} 50 \mathrm{Ti} 50$ & $37 \pm 1$ & $102 \pm 4$ & $189 \pm 3$ & $\mathrm{~Pb} 50 \mathrm{Ti} 50$ & $28 \pm 1$ & $85 \pm 1$ & $130 \pm 2$ \\
\hline $\mathrm{Pb} 30 \mathrm{Ti} 70$ & $42 \pm 1$ & $114 \pm 1$ & $20 \mathrm{I} \pm 2$ & $\mathrm{~Pb} 30 \mathrm{Ti} 70$ & $29 \pm 1$ & $88 \pm 2$ & $142 \pm 4$ \\
\hline Ti 70 Zn 30 & $4 I \pm I$ & $118 \pm 1$ & $20 \mathrm{I} \pm 2$ & Ti 70 Zn 30 & $33 \pm 1$ & $100 \pm 1$ & $167 \pm 1$ \\
\hline Ti $50 \mathrm{Zn} 50$ & $40 \pm 1$ & $|2| \pm 1$ & $197 \pm 1$ & Ti $50 \mathrm{Zn} 50$ & $34 \pm 1$ & $101 \pm 1$ & $|6| \pm 1$ \\
\hline Ti $30 \mathrm{Zn} 70$ & $44 \pm 1$ & $136 \pm 1$ & $198 \pm 1$ & Ti $30 \mathrm{Zn} 70$ & $36 \pm 1$ & $106 \pm 1$ & $153 \pm 1$ \\
\hline $\mathrm{Pb}$ & $182 \pm 1$ & $227 \pm 3$ & $215 \pm 1$ & $\mathrm{~Pb}$ & $87 \pm 2$ & $114 \pm 2$ & $117 \pm 3$ \\
\hline $\mathrm{Ti}$ & $4 I \pm I$ & $\mathrm{I} \mid 4 \pm \mathrm{I}$ & $209 \pm 1$ & $\mathrm{Ti}$ & $28 \pm 1$ & $83 \pm 2$ & $129 \pm 2$ \\
\hline $\mathrm{Zn}$ & $64 \pm 1$ & $205 \pm 1$ & $213 \pm 1$ & $\mathrm{Zn}$ & $4 I \pm I$ & $130 \pm 2$ & $133 \pm 2$ \\
\hline
\end{tabular}

RGB using the image taken with the $380 \mathrm{~nm}$, because of the presence of stray light emitted from the source that influences the true fluorescence signal of the samples.

\section{Multispectral Reflectance Imaging}

In Figure 7, we show selected multispectral reflection images and the false RGB image. We observe that, at $380 \mathrm{~nm}$, the samples that contain titanium white and zinc white show lower reflectance values than the unmixed lead white samples. At $400 \mathrm{~nm}$, the mixtures of lead white and zinc white display higher reflectance values than the other white pigments, while at $420 \mathrm{~nm}$ we observe that the reflectance of the oil samples appears less intense than the yolk ones in the reflectance values (Figure 7).

In the combined false RGB image obtained using the three selected images reported above $(R=380 \mathrm{~nm}$, $\mathrm{G}=400 \mathrm{~nm}, \mathrm{~B}=420 \mathrm{~nm}$ ), we can evidence the presence of the unmixed zinc white and of zinc white in mixtures with lead white as a light blue-green hue, justified by the higher reflectance values at about $400 \mathrm{~nm}$ (green color) and $420 \mathrm{~nm}$ (blue color) compared with the other samples (Table I). Lead white in oil and in egg yolk samples presents higher RGB values, above all at $380 \mathrm{~nm}$ (red color) compared with the other samples, and this makes it recognizable in the "false" RGB image. All the titanium white samples present a blue false color, justified by high reflectance values at about 420 (blue color).

\section{Multispectral Fluorescence Imaging}

Although zinc white can be easily recognized by its fluorescence band peaking at about $380 \mathrm{~nm}$ in the UV range, it can be also well identified by using the visible fluorescence emission. Observing the false RGB image, obtained

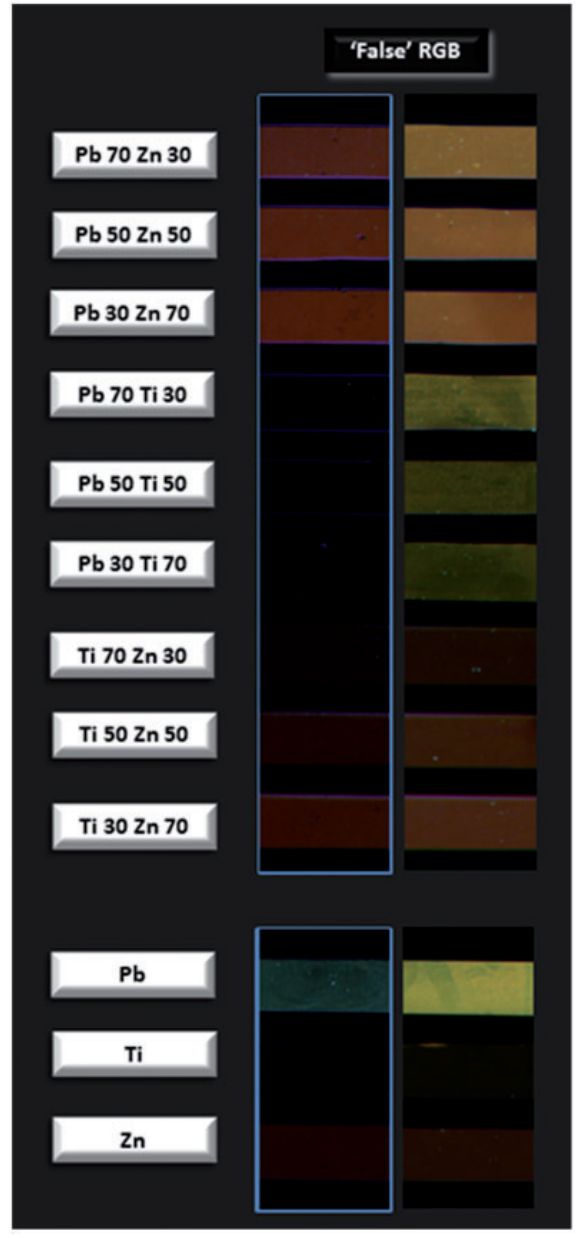

Figure 8. False RGB combination of the fluorescence images taken at $420 \mathrm{~nm}(\mathrm{R}), 470 \mathrm{~nm}(\mathrm{G})$, and $532 \mathrm{~nm}(B)$ of the white samples and their mixtures. The yolk samples are framed in blue rectangles. 
Table 2. False RGB values of the fluorescence images taken at $420 \mathrm{~nm}(\mathrm{R}), 470 \mathrm{~nm}(\mathrm{G})$, and $532 \mathrm{~nm}$ (B) of the white samples and their mixtures.

\begin{tabular}{|c|c|c|c|c|c|c|c|}
\hline $\begin{array}{l}\text { Samples } \\
\text { with yolk }\end{array}$ & $\mathrm{R}$ & G & B & $\begin{array}{l}\text { Samples } \\
\text { with oil }\end{array}$ & $\mathrm{R}$ & G & B \\
\hline $\mathrm{Pb} 70 \mathrm{Zn} 30$ & $79 \pm 2$ & $39 \pm 2$ & $29 \pm 1$ & $\mathrm{~Pb} 70 \mathrm{Za} 30$ & $132 \pm 1$ & $95 \pm 1$ & $45 \pm 1$ \\
\hline $\mathrm{Pb} 50 \mathrm{Zn} 50$ & $83 \pm 1$ & $39 \pm 2$ & $24 \pm 1$ & $\mathrm{~Pb} 50 \mathrm{Zn} 50$ & $130 \pm 3$ & $83 \pm 2$ & $4 I \pm 2$ \\
\hline $\mathrm{Pb} 30 \mathrm{Zn} 70$ & $82 \pm 2$ & $36 \pm 1$ & $19 \pm 2$ & $\mathrm{~Pb} 30 \mathrm{Zn} 70$ & $|2| \pm 6$ & $142 \pm 8$ & $|4| \pm 5$ \\
\hline $\mathrm{Pb} 70 \mathrm{Ti} 30$ & $3 \pm 1$ & $6 \pm 1$ & $4 \pm 1$ & $\mathrm{~Pb} 70 \mathrm{Ti} 30$ & $87 \pm 3$ & $79 \pm 7$ & $27 \pm 2$ \\
\hline Pb 50 Ti 50 & $3 \pm 1$ & $4 \pm 2$ & $4 \pm 1$ & $\mathrm{~Pb} 50 \mathrm{Ti} 50$ & $53 \pm 2$ & $52 \pm 2$ & $14 \pm \mathrm{I}$ \\
\hline $\mathrm{Pb} 30 \mathrm{Ti} 70$ & $5 \pm 1$ & $6 \pm 1$ & $7 \pm 2$ & $\mathrm{~Pb} 30 \mathrm{Ti} 70$ & $42 \pm 5$ & $45 \pm 4$ & $8 \pm 5$ \\
\hline Ti 70 Zn 30 & $14 \pm 1$ & $3 \pm 1$ & $3 \pm 1$ & Ti 70 Zn 30 & $36 \pm 1$ & $23 \pm 1$ & $13 \pm 1$ \\
\hline Ti 50 Zn 50 & $34 \pm 1$ & $12 \pm 1$ & $5 \pm 2$ & Ti 50 Zn 50 & $58 \pm 1$ & $34 \pm 1$ & $20 \pm 2$ \\
\hline Ti $30 \mathrm{Zn} 70$ & $54 \pm 1$ & $21 \pm 1$ & $10 \pm 1$ & Ti 30 Zn 70 & $75 \pm 1$ & $4 I \pm I$ & $26 \pm I$ \\
\hline $\mathrm{Pb}$ & $27 \pm 1$ & $48 \pm 2$ & $43 \pm 3$ & $\mathrm{~Pb}$ & $153 \pm 4$ & $146 \pm 1$ & $52 \pm I$ \\
\hline $\mathrm{Ti}$ & $\mathrm{I} \pm \mathrm{I}$ & $2 \pm 1$ & $\mathrm{I} \pm \mathrm{I}$ & $\mathrm{Ti}$ & $19 \pm 1$ & $19 \pm 1$ & $8 \pm 1$ \\
\hline $\mathrm{Zn}$ & $33 \pm 1$ & $15 \pm 1$ & $7 \pm 1$ & $\mathrm{Zn}$ & $4 I \pm I$ & $25 \pm 2$ & $15 \pm 2$ \\
\hline
\end{tabular}

combining the images taken at $420 \mathrm{~nm}(\mathrm{R}), 470 \mathrm{~nm}(\mathrm{G})$ and $532 \mathrm{~nm}$ (B) (Figure 8), and the RGB average values in Table 2 , we can say that the egg yolk samples can be distinguished from the oil samples due to the strong differences in their RGB values; the unmixed zinc white and the mixture of lead-zinc white samples are well identified by the brown hue due to the higher values at about $532 \mathrm{~nm}$ (red color). Titanium white, as well as titanium white mixed with lead white in egg yolk samples, is dark; the same pigments in oil show similar false color values as titanium in oil. Lead white in oil or in egg yolk presents different false colors; the yolk samples show higher values at $420 \mathrm{~nm}$ (red color) and $470 \mathrm{~nm}$ (green color) compared with the oil samples. The samples with titanium white mixed with zinc white showed an increase of all the RGB values with increasing zinc white both in yolk and oil samples.

\section{Conclusion}

The spectral features of white pigments and white pigment mixtures have been evaluated and discussed through the combined use of reflectance measurements, spectrofluorimetry, and multispectral imaging.

We found that the reflectance measurements are effective in distinguishing lead white in oil from lead white in egg yolk, zinc white in oil from zinc white in egg yolk, and the presence of zinc white when mixed with lead white. The samples containing titanium white, despite the high content of zinc white or lead white, maintain the spectral features of the unmixed titanium samples. With the fluorescence spectra in the visible range we can well distinguish not only the samples that contain zinc white but also the binder in which they have been mixed. We tested the possibility of distinguishing white pigment mixtures combining three multispectral imaging in a false RGB image obtaining good results.

For the multispectral reflectance false RGB image, we have chosen the filters centered at $380 \mathrm{~nm}(\mathrm{R})$ and $400 \mathrm{~nm}(\mathrm{G})$, corresponding to the inflection points of the reflectance spectra of zinc white and titanium white, respectively, and one centered at $420 \mathrm{~nm}(\mathrm{~B})$, at which the reflectance values of all the samples differ mostly from each other. In the false RGB image we can recognize whether the zinc white pigment is mixed with titanium white or with lead white because they have false colors characterized by different RGB values. For the multispectral fluorescence false RGB image, we have chosen the filters centered at $420 \mathrm{~nm}(\mathrm{R}), 470 \mathrm{~nm}(\mathrm{G})$, and $532 \mathrm{~nm}(\mathrm{~B})$. The first two correspond to the emission bands of the titanium white samples and the dried lead white in oil, respectively. The last one transmits a spectral interval in which the fluorescence emitted by zinc white samples is still rather strong and definitely different from that of the other ones.

In the false RGB image we can discriminate if zinc white and its mixtures with other white pigments are blended with linseed oil or with egg yolk by means of their RGB values. The titanium white and its mixtures with yolk appear black, while the ones in oil show a weak false yellow color, due to similar R $(420 \mathrm{~nm})$ and $G(470 \mathrm{~nm})$ values, both higher than B $(532 \mathrm{~nm})$ values, as lead white in oil. Lead white can be detected only if it is mixed with linseed oil or yolk egg without mixing with other white pigments.

\section{Conflict of Interest}

The authors report there are no conflicts of interest.

\section{Funding}

This research received no specific grant from any funding agency in the public, commercial, or not-for-profit sectors. 


\section{References}

I. H. Kühn. "Zinc White". In: R.L. Feller (ed.) Artists' Pigments: A Handbook of Their History and Characteristics. Vol. I. Washington, D.C.: National Gallery of Art, 1997, pp.169-186.

2. J. Rutherford, R.J. Gettens, H. Kühn, W.T. Chase. "Lead White". In: A. Roy (ed.) Artists' Pigments: A Handbook of Their History and Characteristics, Vol. 2. Washington, D.C.: National Gallery of Art, 1993, pp.67-8I.

3. M. Laver. "Titanium Dioxide Whites". In: E.W. FitzHugh (ed.) Artists' Pigments: A Handbook of Their History and Characteristics, Vol. 3. Washington, D.C.: National Gallery of Art, 1997, pp.295-355.

4. F.C. Izzo, K.J. van den Berg, H. van Keulen, B. Ferriani, et al. "Modern Oil Paints-Formulations, Organic Additives and Degradation: Some Case Studies". In: K.J. van den Berg (ed.) Issues in Contemporary Oil Paint. Switzerland: Springer International Publishing, 2014, pp.75-104.

5. Y. Maor, A. Murray, B. Kaiser. Using XRF for Semi-Quantitative Analysis in a Study of Delaminating Paint. Paper presented at: Art 2008: 9th International Conference on NDT of Art. Jerusalem, Israel, May 2008. Pp. I-10.

6. A. Martins, J. Coddington, G. Van der Snickt, B. van Driel, et al. "Jackson Pollock's Number IA, 1948: A Non-Invasive Study Using Macro-X-ray Fluorescence Mapping (MA-XRF) and Multivariate Curve Resolution-Alternating Least Squares (MCR-ALS) Analysis". Herit. Sci. 2016. 4(I): 33.

7. R. Klockenämper, A. von Bohlen, L. Moens, W. Devos. "Analytical Characterization of Artists' Pigments Used in Old and Modern Paintings by Total-Reflection X-ray Fluorescence". Spectrochim. Acta, Part B. 1993. 48(2): 239-246.

8. Z. Szökefalvi-Nagy, I. Demeter, A. Kocsonya, I. Kovács. "Nondestructive XRF Analysis of Paintings". Nucl. Instrum. Methods Phys. Res., Sect. B. 2004. 226(I-2): 53-59. 10.1016/j.nimb. 2004.03.074.

9. C. Miliani, F. Rosi, A. Burnstock, B.G. Brunetti, et al. "Non-Invasive In-Situ Investigations Versus Micro-Sampling: A Comparative Study on a Renoir Painting". Appl. Phys. A. 2007. 89(4): 849-856.

I0. J.L. Ferrero, C. Roldán, D. Juanes, E. Rollano, et al. "Analysis of Pigments from Spanish Works of Art Using a Portable EDXRF Spectrometer". X-ray Spectrom. 2002. 3I(6): 44I-447.

II. P. Targowski, M. Iwanicka, G. Van der Snickt, M. Alfeld, et al. "Optical Coherence Tomography: Its Role in the NonInvasive Structural Examination and Conservation of Cultural Heritage Objects-A Review”. Appl. Phys. A. 2012. 106(2): 265-277.

12. S.E.J. Bell, L.A. Fido, S.J. Speers, W.J. Armstrong, et al. "Forensic Analysis of Architectural Finishes Using Fourier Transform Infrared and Raman Spectroscopy, Part II: White Paint". Appl. Spectrosc. 2005. 59(II): 1340-1346.

I3. A. Daveri, B. Doherty, P. Moretti, C. Grazia, et al. "An Uncovered XIII Century Icon: Particular Use of Organic Pigments and Gilding Techniques Highlighted by Analytical Methods". Spectrochim. Acta, Part A. 2015. 135: 398-404.

14. H.G.M. Edwards, J.M. Chalmers. Raman Spectroscopy in Archaeology and Art History. Cambridge, UK: Royal Society of Chemistry, 2005.

15. L. Burgio, R.J. Clark. "Library of FT-Raman Spectra of Pigments, Minerals, Pigment Media and Varnishes, and Supplement to Existing Library of Raman Spectra of Pigments with Visible Excitation." Spectrochim. Acta, Part A. 200I. 57(7): |49|-521.

16. L. Burgio, K. Melessanaki, M. Doulgeridis, R.J.H. Clark, et al. "Pigment Identification in Paintings Employing Laser Induced Breakdown Spectroscopy and Raman Microscopy". Spectrochim. Acta, Part B. 200I. 56(6): 905-913.
17. P. Vandenabeele, J. Tate, L. Moens. "Nondestructive Analysis of Museum Objects by Fibre-Optic Raman Spectroscopy." Anal. Bioanal. Chem. 2007. 387(3): 8I3-9.

18. C. Miliani, F. Rosi, B.G. Brunetti, A. Sgamellotti. "In Situ Noninvasive Study of Artworks: The MOLAB Multitechnique Approach". Acc. Chem. Res. 2010. 43(6): 728-738.

19. T. Aguayo, E. Clavijo, A. Villagrán, F. Espinosa, et al. "Raman Vibrational Study of Pigments with Patrimonial Interest for the Chilean Cultural Heritage". J. Chil. Chem. Soc. 20I0. 55(3): 347-35I.

20. R. Mazzeo, E. Joseph, S. Prati, A. Millemaggi. "Attenuated Total Reflection-Fourier Transform Infrared Microspectroscopic Mapping for the Characterisation of Paint Cross-Sections". Anal. Chim. Acta. 2007. 599(I): 107-117.

2I. M. Picollo, M. Bacci, D. Magrini, B. Radicati, et al. "Modern White Pigments: Their Identification by Means of Noninvasive Ultraviolet, Visible, and Infrared Fiber Optic Reflectance Spectroscopy". Modern Paints Uncovered Symposium, Tate modern, London, May 16-19, 2006. Editors T.J.S. Learner, P. Smithen, J.W. Krueger, M. Schilling. The Getty Conservation Institute, Los Angeles, 2007, Pp. I 18-128.

22. M. Bacci, M. Picollo, G. Trumpy, M. Tsukada, et al. "Non-Invasive Identification of White Pigments on 20th-Century Oil Paintings by Using Fiber Optic Reflectance Spectroscopy". J. Am. Inst. Conserv. 2007. 46(I): 27-37.

23. M. Bacci, A. Casini, C. Cucci, M. Picollo, et al. "Non-Invasive Spectroscopic Measurements on the 'Portrait of the Stepdaughter' by Giovanni Fattori: Identification of Pigments and Colorimetric Analysis". J. Cult. Herit. 2003. 4(4): 329-336.

24. R.D. la Rie. "Fluorescence of Paint and Varnish Layers (Part I)". Stud. Conserv. 1982. 27(I): I-7.

25. C. Daffara. A Study of UV Fluorescence Emission of Painting Materials. In: Proceedings of the 8th International Conference on NonDestructive Investigations and Microanalysis for the Diagnostics and Conservation of the Cultural and Environmental Heritage. Lecce, Italy, 15-19 May 2005. Pp. I-I4.

26. C. Clementi, F. Rosi, A. Romani, R. Vivani, et al. "Photoluminescence Properties of Zinc Oxide in Paints: A Study of the Effect of SelfAbsorption and Passivation". Appl. Spectrosc. 2012. 66(10): |233-124I.

27. J.J. Rorimer. Ultraviolet Rays and their Use in the Examination of Works of Art. New York: Metropolitan Museum of Art, 1931.

28. E. Isacco, J. Darrah. "The Ultraviolet-Infrared Method of Analysis, a Scientific Approach to the Study of Indian Miniatures". Artibus Asiae. 1993. 53(3-4): 470-491.

29. A.V. Aldovrandi. "Caratterizzazione dei Materiali Pittorici Nelle Pitture Murali Mediante Tecniche Fotografiche". OPD Restauro. 20I0. 22: $55-80$.

30. A. Cosentino. "Practical Notes on Ultraviolet Technical Photography for Art Examination". Conserv. Património. 2015. 21: 53-62.

3I. A. Cosentino. "Identification of Pigments by Multispectral Imaging: A Flowchart Method". Herit. Sci. 2014. 2(I): 8.

32. L. Pronti, P. Ferrara, F. Uccheddu, A. Pelagotti, et al. Identification of Pictorial Materials by Means of Optimized Multispectral Reflectance Image Processing. 2015 IEEE International Workshop on Information Forensics and Security (WIFS). IEEE, Rome, Italy, 16-19 November 20I5. Pp. I-6.

33. C. Cucci, J.K. Delaney, M. Picollo. "Reflectance Hyperspectral Imaging for Investigation of Works of Art: Old Master Paintings and Illuminated Manuscripts". Acc. Chem. Res. 2016. 49(10): 2070-2079.

34. J.K. Delaney, J.G. Zeibel, M. Thoury, R. Littleton, et al. "Visible and Infrared Imaging Spectroscopy of Picasso's Harlequin Musician: Mapping and Identification of Artist Materials in Situ". Appl. Spectrosc. 2010. 64(6): 584-594.

35. R. Siddall, V. Walsh, N. Eastaugh, T. Chaplin. Pigment Compendium: A Dictionary of Historical Pigments. Amsterdam, The Netherlands: Elsevier Butterworth-Heinemann, 2004. 
36. M. Thoury, J.-P. Echard, M. Réfrégiers, B. Berrie, et al. "Synchrotron UV-Visible Multispectral Luminescence Microimaging of Historical Samples". Anal. Chem. 20II. 83(5): 1737-1745.

37. L. Pronti. Multispectral Imaging of Paintings. Potentialities and Limitations of the Technique in Relation with the Chemical and Optical Properties of the Pictorial Materials. [Doctoral Thesis]
Rome, Italy: Sapienza University of Rome and Avignon, France: University of Avignon, 2016.

38. T. Moon, M.R. Schilling, S. Thirkettle. "A Note on the Use of FalseColor Infrared Photography in Conservation". Stud. Conserv. 1992. 37(I): 42-52. 